\title{
PENGARUH PENGETAHUAN ZAKAT DAN KEPERCAYAAN KEPADA BAZNAS KABUPATEN KUANTAN SINGINGI TERHADAP MINAT MUZAKKI MEMBAYAR ZAKAT
}

\author{
Zulfadli Hamzah ${ }^{1}$ \& Izzatunnafsi Kurniawan ${ }^{2}$ \\ $1 \& 2$ Fakultas Agama Islam, Universitas Islam Riau \\ Email: zulfadlihamzah@fis.uir.ac.id,izzatunnafsi.k@gmail.com
}

\begin{abstract}
ABSTRAK
Tujuan dari penelitian ini adalah untuk memperoleh bukti empiris apakah pengetahuan zakat dan kepercayaan kepada Baznas Kabupaten Kuantan Singingi mempengaruhi minat muzakki membayar zakat. Populasinya adalah jumlah muzakki pada tahun 2018 sebanyak 4.232 orang dan sampelnya sebanyak 98 orang. Untuk variabel dependen (Y) yaitu minat muzakki membayar zakat, untuk variabel independen (X) meliputi : pengetahuan zakat (X1), dan kepercayaan (X2). Jenis penelitian yang digunakan pada penelitian ini adalah jenis penelitian lapangan (Field Research), yaitu memaparkan dan menggambarkan keadaan serta fenomena yang lebih mengenai situasi yang terjadi. Pengumpulan data menggunakan angket dan dokumentasi dan di analisis menggunakan regresi linier berganda melalui program SPSS versi 23. Dari hasil uji t (parsial) maupun uji F (simultan) didapatkan bahwa pengetahuan zakat dan kepercayaan kepada Baznas secara bersama-sama dan parsial berpengaruh signifikan terhadap variabel minat muzakki membayar zakat di Baznas Kabupaten Kuantan Singingi.
\end{abstract}

Kata kunci : Pengetahuan, Kepercayaan, Minat, Zakat, Baznas.

\begin{abstract}
The objective in this study was to obtain the empirical evidence whether knowledge about zakat and belief to Baznas give the influence of muzakki interest to pay zakat or not at Kuantan Singingi Regency. Total population in this study were 4.232 muzakki in 2018 and samples were 98 muzakki. Dependent variable in this study is muzakki interest in paying zakat $(Y)$ and independent variables $(X)$ consist of the knowledge of zakat (X1) and belief (X2). This is field reseach means presenting and describing the condition and phenomena more deeply dealing the situation happened. In collecting data, it used questionnaire, then analyzing by using SPSS version 23. Based on data analyzing both $t$ and $F$, it showed that knowledge about zakat and belief to baznas have significant effect on the muzakki interest in paying zakat simoultantly and partialy.
\end{abstract}

Keywords : Knowledge, Belief, Interest, Zakat, Baznas. 


\section{PENDAHULUAN}

Bagi kehidupan di dunia, kemiskinan merupakan bahaya besar bagi umat manusia dan tidak sedikit umat yang jatuh peradabannya hanya karena kefakiran. Karena itu seperti sabda Nabi Muhammad SAW yang menyatakan bahwa kefakiran itu mendekati pada kekufuran. Diantara cara menanggulangi kefakiran adalah dengan adanya dukungan atau tolong menolong orang yang mampu untuk mengeluarkan harta kekayaannya berupa dana zakat kepada mereka yang kekurangan akan tetapi tidak semua bentuk tolong menolong itu baik, melainkan ada juga yang tidak baik. Tolong menolong yang baik adalah apabila mengarah pada kebaikan dan ketaqwaan sesuai dengan petunjuk agama.

Adapun tolong menolong yang menyangkut masalah dosa dan permusuhan termasuk perkara yang dilarang agama. Tolong menolong bebas dilakukan dengan siapapun (termasuk non muslim), selama tidak menyangkut masalah akidah dan ibadah. Dalam hal akidah dan ibadah tidak ada kompromi antara agama yang satu dengan yang lain.

Zakat berperan penting dalam kehidupan sosial, karena fungsi zakat sendiri adalah distribusi kekayaan agar perekonomian masyarakat lebih merata. Untuk memaksimal pengelolaan zakat, infaq, shodaqoh dan wakaf, maka pemerintah membentuk badan yang mengelola dana zakat, infaq, shodaqoh dan wakaf yaitu Badan Amil Zakat (BAZ) yang dibentuk oleh pemerintah dan Lembaga Amil Zakat (LAZ) yang dibentuk oleh masyarakat kemudian dikukuhkan oleh pemerintah. Dalam hal ini lembaga zakat berfungsi untuk melakukan pencatatan dan pelaporan atas penerimaan dan pengalokasian zakat.
Masyarakat Kabupaten Kuantan Singingi penduduknya mayoritas beragama Islam dan mata pencahariannya beragam seperti halnya, PNS (Pegawai Negeri Sipil), pengusaha, pedagang, buruh, petani, dan lain sebagainya. Dalam ajaran agama Islam, bekerja merupakan ibadah, dimana hakikat hukum ibadah adalah wajib. Sehingga dapat ditarik kesimpulan bahwa bekerja adalah kewajiban bagi umat muslim. Bagi seorang muslim, makna makna bekerja berarti niat yang kuat mewujudkan hasil kerja yang optimal, bukan hanya memberikan nilai rata-rata.

Kepercayaan sangat erat kaitannya dengan persepsi karena persepsi merupakan proses pengolahan mental secara sadar terhadap stimulus sensori. Kepercayaan masyarakat adalah hal yang mendasar bagi Baznas Kabupaten Kuantan Singingi dalam menjalin hubungan dengan pelanggan (muzakki). Kepercayaan didasari atas adanya kepuasan dari muzakki. Dari sisi pengumpulan zakat, permasalahan yang paling sering terjadi dan paling besar adalah adanya kesenjangan yang sangat lebar antara potensi zakat dengan realisasi pengumpulan zakat serta pendistribusian zakat.

Berdasarkan hasil wawancara peneliti bersama salah satu pengurus Baznas Kabupaten Kuantan Singingi, bapak Ramli S.Ag beliau menuturkan bahwa jumlah muzakki di Baznas Kabupaten Kuantan Singingi terus mengalami peningkatan, hal itu tentu tidak terlepas dari sosialisasi yang dilakukan Baznas kepada masyarakat tentang wajibnya zakat baik melalui ceramah agama, maupun media. Beliau juga menjelaskan bahwa Baznas juga objektif tentang penyaluran zakat yang dititipkan para muzakki. 
Baznas juga selalu memberikan informasi kepada masyarakat melalui media online maupun cetak dalam berbagai hal yang berkaitan dengan Baznas. Selain itu Baznas juga mengembangkan sistem informasi manajemen berbasis teknologi informasi. Baznas Kabupaten Kuantan Singingi juga memberikan laporan pertanggung jawaban kepada Kementerian Agama dan Baznas Provinsi Riau. Hal itu dilakukan agar kredibilitas Baznas tetap terjaga dan kepercayaan muzzaki meningkat kepada Baznas Kabupaten Kuantan Singingi.

\section{TINJAUAN PUSTAKA Pengertian Zakat}

Secara bahasa, zakat berarti tumbuh (nummuw) dan bertambah (zidayah). Jika diucapkan, zaka al-zar artinya adalah tanaman itu tumbuh dan bertambah. Jika diucapkan zakat alnafaqah, artinya nafkah tumbuh dan bertambah jika diberkati. Adapun zakat menurut syara', berarti hak yang wajib (dikeluarkan dari harta). (Al-Zuhaily, 1995)

Zakat bertujuan untuk mengatasi kesenjangan sosial antara si kaya dengan si miskin. Selain itu, zakat juga dapat mempererat hubungan antara manusia dengan sang Pencipta melindungi kekayaan itu dari kebinasaan.

Adapun harta yang dikeluarkan menurut syara', dinamakan zakat karena harta itu akan bertambah dan memelihara dari kebinasaan. Maknamakna zakat secara terminologis di atas bisa terkumpul dalam ayat berikut:

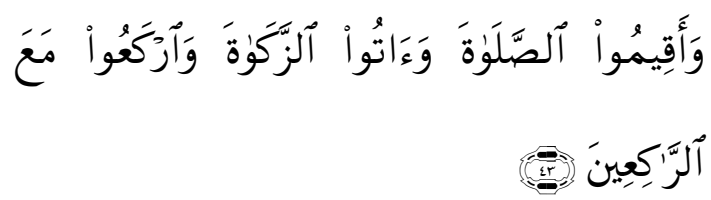

Artinya : Dan dirikanlah shalat, tunaikanlah zakat dan ruku'lah beserta orang-orang yang ruku'. (Q.S. 2 : 43)

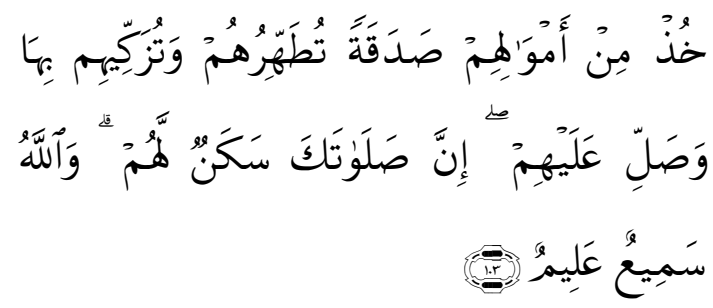

Artinya : "Ambillah zakat dari sebagian harta mereka, dengan zakatmu itu kamu membersihkan dan mensucikan mereka, dan berdo'alah untuk mereka. Sesungguhnya do'a kamu itu (menjadi) ketentraman jiwa bagi mereka. Dan Allah Maha Mendengar lagi Maha Mengetahui”. (Q.S. 9 : 103)

\begin{tabular}{lcc}
\multicolumn{1}{c}{ Maksud } & zakat itu & akan \\
menyucikan & orang & yang \\
mengeluarkannya & dan & akan
\end{tabular}
menumbuhkan pahalanya. Adapun zakat menurut syara', berarti hak yang wajib (dikeluarkan dari) harta. Mazhab Maliki mendefinisikan zakat dengan, mengeluarkan sebagian yang khusus dari harta yang khusus pula yang telah mencapai nishab (batas kuantitas yang mewajibkan zakat) kepada orang-orang yang berhak menerimanya (mustahiq) Dengan catatan, kepemilikan itu penuh dan mencapai haul (setahun), bukan barang tambang bukan barang pertanian.

Zakat adalah ibadah dalam harta yang sebagaimana mengandung hikmah dan manfaat yang demikian besar dan mulia, baik yang berkaitan dengan orang yang berzakat (muzakki), penerimanya (mustahik), harta yang dikeluarkan zakatnya, maupun bagi masyarakat keseluruhan. Hikmah dan manfaat zakat yaitu salah satunya sebagai perwujudan keimanan kepada Allah SWT, menumbuhkan akhlak yang mulia dengan rasa kemanusiaan yang tinggi, menghilangkan sifat kikir, rakus dan matrealistis, menumbuhkan ketenangan 
hidup, sekaligus membersihkan dan mengembangkan harta yang dimiliki.

\section{Pengetahuan Zakat}

Pengetahuan adalah informasi yang telah diproses dan diorganisasikan untuk memperoleh pemahaman, pembelajaran dan pengalaman yang terakumulasi sehingga bisa diaplikasikan ke dalam masalah /proses bisnis tertentu. Informasi yang diproses untuk mengekstrak implikasi kritis dan merefleksikan pengalaman masa lampau menyediakan penerima dengan pengetahuan yang terorganisasi dengan nilai yang tinggi.

Pengetahuan zakat adalah pengetahuan masyarakat tentang zakat, tujuan dan manfaat zakat, dampak yang akan diperoleh dari membayar zakat yang akan melahirkan budaya berzakat masyarakat sebagai suatu kewajiban yang harus ditunaikan. Pengetahuan masyarakat tentang zakat, cara pandangan masyarakat tentang sangat kental dengan nuansa fiqih harus ditambah dengan cara pandang yang memungkinkan zakat dapat diberdayakan. Cara pandang ekonomi dan sosial agaknya dapat ditambahkan dalam melihat kewajiban zakat. Jika selama sebagian masyarakat memandang zakat sebagai iman yang terlepas kaitanya dengan persoalan sosial dan ekonomi. Maka saat ini zakat harus dipandang sebagai sumber kekuatan ekonomi yang dapat dipergunakan untuk menyelesaikan berbagai permasalahan sosial umat Islam. (Bukhori, 2009)

\begin{tabular}{llr}
\multicolumn{2}{c}{ Faktor pengetahuan } & zakat \\
memiliki nilai yang penting & dalam \\
konteks pemberdayaan zakat. Sebab
\end{tabular}

pengetahuan sesorang tentang sesuatu akan mempengaruhi perilakunya. Dalam filsafat fenomenologis dikemukakan bahwa tingkah laku manusia merupakan konsekuensi dari sejumlah pandangan atau doktrin yang hidup dikepala manusia yang bersangkutan. Sebagai contoh membayar zakat secara langsung kepada mustahiq (penerima zakat) dan membayar zakat melalui lembaga.

Adapun yang menjadi indikator pengetahuan zakat dalam penelitian ini adalah :

1. Mengetahui apa itu definisi zakat

2. Memahami hukum-hukum yang berkaitan dengan zakat

3. Hikmah dan Manfaat zakat

4. Rukun zakat

5. Syarat zakat

6. Harta yang wajib di zakati

7. Mustahiq Zakat

\section{Kepercayaan}

Kepercayaan adalah kemauan seseorang untuk bertumpu pada orang lain dimana kita memiliki keyakinan padanya. Kepercayaan lahir dari suatu proses secara perlahan kemudian terakumulasi menjadi suatu bentuk kepercayaan, dengan kata lain kepercayaan adalah keyakinan kita pada suatu produk atau atribut tertentu. Keyakinan ini muncul dari persepsi dari pembelajaran dan pengalaman. (Taufiq Amir, 2005)

Kepercayaan terhadap lembaga zakat dalam penelitian ini didefinisikan sebagai kemauan atau minat muzakki untuk menggunakan lembaga zakat dalam penyaluran zakatnya terhadap mustahiq zakat karena muzakki yakin lembaga tersebut profesional, amanah dan transparan. Disamping akan menumbuhkan rasa kepercayaan 
terhadap masyarakat, dana zakat yang terkumpul dan tersalurkan akan semakin meningkat dan optimal dalam pemanfaatannya. Dengan demikian masyarakat akan berminat dan berkeinginan berzakat pada lembaga amil zakat apabila mereka percaya pada lembaga zakat.

Adapun yang menjadi indikator kepercayaan dalam penelitian ini adalah (Wibowo, 2006) :
1. Keterbukaan
2. Kejujuran
3. Integritas
4. Kompeten
5. Sharing
6. Penghargaan
7. Akuntabilitas

\section{Minat Membayar Zakat}

Minat merupakan motivasi yang mendorong orang untuk melakukan apa saja yang mereka inginkan. Setiap minat akan memuaskan suatu kebutuhan. Dalam pelaksanaan fungsinya kehendak berhubungan dengan pikiran dan perasaan. Pikiran mempunyai kecenderungan bergerak dalam sektor rasional analisis, sedang perasaan yang bersifat halus lebih mendambakan kebutuhan. Sedangkan akal berfungsi sebagai pengingat fikiran dan perasaan dalam koordinasi yang harmonis, agar kehendak bisa diatur sebaik-baiknya.

Menurut djaali (2012) minat adalah rasa suka dan rasa ketertarikan pada suatu hal atau aktivitas tanpa ada yang menyuruh. Minat pada dasarnya adalah penerimaan akan suatu hubungan antara diri sendiri dengan sesuatu di luar diri. Semakin kuat atau dekat hubungan tersebut maka semakin besar minatnya.

Menurut Slameto

"interest is persisting tedency to pay attention to and enjoy some activity or content", yang artinya minat adalah kecendrungan yang tetap untuk memperhatikan dan mengenang beberapa kegiatan. Kegiatan disini adalah kegiatan yang diminati oleh seseorang, di perhatikan terus-menerus yang disertai dengan rasa senang. Minat adalah suatu rasa lebih suka dan ketertarikan kepada suatu hal atau aktivitas tanpa ada yang menyuruh.

Adapun yang menjadi indikator Minat dalam penelitian ini adalah (Mandasari, 2011) :
1. Ketertarikan (interest)
2. Keingingan (desire)
3. Keyakinan (cinviction)

\section{METODE PENELITIAN}

Jenis penelitian yang digunakan adalah penelitian lapangan (Field Research) yaitu memaparkan dan menggambarkan keadaan serta fenomena yang lebih jelas mengenai situasi yang terjadi (Leksono, 2013). Metode yang digunakan dalam penelitian ini adalah penelitian kausalitas yaitu desain penelitian yang disusun untuk meneliti kemungkinan adanya hubungan sebab akibat antar variabel. Oleh karena itu, penelitian ini menggunakan model regresi berganda dimana variabel dependen (Y) yaitu minat muzakki membayar zakat, untuk variabel independen (X) meliputi : Pengetahuan Zakat (X1), dan Kepercayaan (X2).

Populasi dalam penelitian ini adalah seluruh muzakki yang membayar zakat di Baznas Kabupaten Kuantan Singingi sebanyak 4.232 orang.

Adapun teknik penentuan jumlah sampel dalam penelitian ini menggunakan rumus slovin sebagai berikut (Sanusi, 2014) :

$$
\begin{aligned}
\mathrm{n} & =\frac{N}{1+N . e 2} \\
\mathrm{n} & =\frac{4.232}{1+(4.232)(10 \%)^{2}}
\end{aligned}
$$


$=97,69=98$ Orang

Keterangan:

$\mathrm{n}$ = Ukuran Sampel

$\mathrm{N}=$ Ukuran Populasi

$\mathrm{e}=$ Persentase kelonggaran ketelitian karena kesalahan pengambilan sampel.

Dalam penelitian ini jumlah populasi $(\mathrm{N})=4.232$ orang, dengan nilai kritis (e) sebesar 10\% maka ukuran sampel 98 orang.

Untuk analisis data penelitian ini menggunakan uji validitas dan uji realibilitas. Sedangkan untuk uji hipotesis dalam penelitian ini menggunakan uji T dan Uji F.

\section{HASIL DAN PEMBAHASAN}

\section{Uji Validitas}

Pengukuran validitas dilakukan dengan menggunakan rumus Corrected Item-Total Correlation dengan taraf signifikan $5(\alpha=0,05)$ artinya suatu item dianggap valid jika berkorelasi signifikan terhadap skor total.

Tabel 1. Hasil Uji Validitas

\begin{tabular}{ccccc}
\hline Variabel & Item & $\begin{array}{c}\text { Corrected Item- } \\
\text { Total Correlation } \\
\text { (r Hitung) }\end{array}$ & $\mathbf{r}$ tabel & $\begin{array}{c}\text { Keterangan } \\
\text { Hasil }\end{array}$ \\
\hline $\mathbf{X 1}$ & Pernyataan & 0.297 & 0.202 & Valid \\
\hline Item 1 & 0.209 & 0.202 & Valid \\
\hline Item 2 & 0.639 & 0.202 & Valid \\
\hline Item 3 & 0.401 & 0.202 & Valid \\
\hline Item 4 & 0.633 & 0.202 & Valid \\
\hline Item 5 & 0.607 & 0.202 & Valid \\
\hline Item 6 & 0.633 & 0.202 & Valid \\
\hline Item 7 & 0.290 & 0.202 & Valid \\
\hline Item 8 & 0.477 & 0.202 & Valid \\
\hline Item 9 & 0.402 & 0.202 & Valid \\
\hline Item 10 & 0.357 & 0.202 & Valid \\
\hline Item 11 & 0.337 & 0.202 & Valid \\
\hline Item 12 & 0.328 & 0.202 & Valid \\
\hline Item 13 & 0.277 & 0.202 & Valid \\
\hline Item 14 & 0.304 & 0.202 & Valid \\
\hline Item 15 & 0.500 & 0.202 & Valid \\
\hline Item 16 & 0.477 & 0.202 & Valid \\
\hline
\end{tabular}

Sumber: Data Olahan SPSS (2019)

Jika $r$ hitung > $r$ tabel maka itemitem pernyataan dinyatakan valid. Dan jika $r$ hitung < $r$ tabel maka item-item pernyataan dinyatakan tidak valid. Diketahui nilai $r$ tabel sebesar 0,202 (lihat tabel r) dan nilai ini dibandingkan dengan nilai $r$ hitung. Nilai $r$ hitung dalam uji ini adalah pada kolom ItemTotal Statistics (Corrected Item-Total Correlation). Dan dari tabel di atas menunjukkan bahwa butir pernyataan mempunyai nilai korelasi yang lebih besar dari $r$ tabel. Sehingga seluruh item- 
item variabel dinyatakan valid dan layak untuk dianalisis..

\section{Uji Realibilitas}

Uji reliabilitas digunakan teknik Cronbach Alpha dimana instrumen dapat dikatakan handal atau reliabel bila memiliki koefisien kehandalan sebesar >
0,6. Reliabilitas ini akan dilakukan pada butir-butir pernyataan yang telah memiliki kevalidan pada uji validitas sebelumnya, dan jumlah butir pernyataan yang dapat diuji pada uji reliabilitas ini sebanyak 98 butir. Dimana hasil pengujiannya dapat dilihat pada tabel berikut:

Tabel 2. Hasil Uji Realibilitas

\begin{tabular}{|c|c|c|c|c|}
\hline \multirow[t]{2}{*}{ Variabel } & \multirow{2}{*}{$\begin{array}{c}\text { Item } \\
\text { Pernyataan } \\
\end{array}$} & \multirow{2}{*}{$\begin{array}{c}\text { Cronbach } \\
\text { Alpha }\end{array}$} & \multirow{2}{*}{$\begin{array}{c}\text { Koefisien } \\
\text { Alpha } \\
\end{array}$} & \multirow[t]{2}{*}{ Keterangan Hasil } \\
\hline & & & & \\
\hline \multirow[t]{7}{*}{$\mathrm{X} 1$} & Item 1 & .832 & 0.6 & Reliabel \\
\hline & Item 2 & .835 & 0.6 & Reliabel \\
\hline & Item 3 & .815 & 0.6 & Reliabel \\
\hline & Item 4 & .827 & 0.6 & Reliabel \\
\hline & Item 5 & .816 & 0.6 & Reliabel \\
\hline & Item 6 & .817 & 0.6 & Reliabel \\
\hline & Item 7 & .816 & 0.6 & Reliabel \\
\hline \multirow[t]{9}{*}{$\mathrm{X} 2$} & Item 8 & .832 & 0.6 & Reliabel \\
\hline & Item 9 & .824 & 0.6 & Reliabel \\
\hline & Item 10 & .827 & 0.6 & Reliabel \\
\hline & Item 11 & .829 & 0.6 & Reliabel \\
\hline & Item 12 & .830 & 0.6 & Reliabel \\
\hline & Item 13 & .831 & 0.6 & Reliabel \\
\hline & Item 14 & .833 & 0.6 & Reliabel \\
\hline & Item 15 & .839 & 0.6 & Reliabel \\
\hline & Item 16 & .823 & 0.6 & Reliabel \\
\hline \multirow[t]{3}{*}{$\mathrm{Y}$} & Item 17 & .823 & 0.6 & Reliabel \\
\hline & Item 18 & .827 & 0.6 & Reliabel \\
\hline & Item 19 & .822 & 0.6 & Reliabel \\
\hline
\end{tabular}

Sumber : Data Olahan SPSS (2019)

\section{Uji Multikolinearitas}

Uji Multikolinearitas digunakan untuk mengetahui ada atau tidaknya hubungan linear antara variabel independen dalam model regresi. Salah satu cara untuk mengetahui ada tidaknya multikolinearitas pada suatu model regresi adalah dengan melihat nilai tolerance dan VIF (Variance Inflation Factor). Jika nilai tolerance $>0,1$ dan VIF $<10$, maka dapat diartikan bahwa tidak terdapat multikolinearitas pada penelitian tersebut. Hasil uji multikolinearitas dapat dilihat dari tabel berikut 
2020, Jurnal Tabarru' : Islamic Banking and Finance 3 (1) : 30 - 40

Tabel 3. Analisis Regresi Berganda

\begin{tabular}{llccc}
\hline \multirow{2}{*}{ Model } & \multicolumn{2}{c}{ Unstandardized Coefficients } & \multicolumn{2}{c}{ Standardized Coefficients } \\
\cline { 2 - 5 } & B & Std. Error & Beta \\
\hline \multirow{2}{*}{ (Constant) } & 1.319 & 1.299 & .495 \\
1 & Pengetahuan & .206 & .035 & .328 \\
\cline { 3 - 5 } Kepercayaan & .139 & .035 &
\end{tabular}

Berdasarkan tabel diatas, maka dapat disusun persamaan regresi berganda sebagai berikut:

$$
\mathrm{Y}=1,319+0.495 \mathrm{X} 1+0,328 \mathrm{X} 2
$$

Arti angka-angka dalam persamaan regresi diatas adalah:

1) Nilai konstanta (a) sebesar 1.319. Artinya adalah apabila pengetahuan dan kepercayaan diasumsikan nol (0), maka minat (Y) bernilai 1.319.

2) Nilai koefisien regresi variabel pengetahuan (X1) sebesar 0,495. Artinya adalah bahwa setiap peningkatan faktor pengetahuan sebesar 1 satuan maka akan meningkatkan minat (Y) sebesar
0,495 dengan asumsi variabel X2 tetap.

3) Nilai koefisien regresi variabel kepercayaan (X2) sebesar 0,328. Artinya adalah bahwa setiap peningkatan faktor kepercayaan sebesar 1 satuan maka akan meningkatkan minat (Y) sebesar 0,328 dengan asumsi variabel $\mathrm{X} 1$ tetap.

\section{Uji Parsial (Uji T)}

Uji-t dilakukan untuk mengetahui pengaruh setiap variabel bebas terhadap variabel terikat. Uji Parsial (Uji-t) menggunakan bantuan komputer program SPSS for Windows versi 23.0, maka dapat dilihat tabel dibawah ini:

Tabel 4. Hasil Uji T

Coefficients $^{\mathrm{a}}$

\begin{tabular}{|c|c|c|c|c|c|c|}
\hline \multirow[t]{2}{*}{ Model } & & \multicolumn{2}{|c|}{ Unstandardized Coefficients } & $\begin{array}{l}\text { Standardized } \\
\text { Coefficients }\end{array}$ & \multirow[t]{2}{*}{$\mathrm{t}$} & \multirow[t]{2}{*}{ Sig. } \\
\hline & & $\mathrm{B}$ & Std. Error & Beta & & \\
\hline \multirow{3}{*}{1} & (Constant) & 1.319 & 1.299 & & 1.015 & .313 \\
\hline & Pengetahuan & .206 & .035 & .495 & 5.951 & .000 \\
\hline & Kepercayaan & .139 & .035 & .328 & 3.943 & .000 \\
\hline
\end{tabular}

a. Dependent Variable: Minat

Sumber : Data Olahan SPSS (2019)

Dari hasil pengolahan diatas dapat diketahui bahwa:

1. Nilai t hitung variabel pengetahuan (X1) sebesar 5,951 dan nilai t tabel sebesar 1,671 dengan tingkat signifikan sebesar 0,05 dan derajat kebebasan sebesar 95 (dk=n-k-1(982-1)) maka akan terlihat bahwa : $\mathrm{t}$ 
hitung > t tabel atau 5,951>1,671. Hal ini menunjukkan bahwa Ho ditolak dan Ha diterima, sehingga dapat dikatakan bahwa terdapat pengaruh yang signifikan antara pengetahuan terhadap minat muzzaki membayar zakat.

2. Nilai t hitung variabel kepercayaan (X2) sebesar 3,943 dan nilai t tabel sebesar 1,671 dengan tingkat signifikan sebesar 0,05 dan derajat kebebasan sebesar 95 (dk=n-k-1(982-1)) maka akan terlihat bahwa : $\mathrm{t}$ hitung > t tabel atau 3,943>1,671. Hal ini menunjukkan bahwa Ho ditolak dan $\mathrm{Ha}$ diterima, sehingga dapat dikatakan bahwa terdapat pengaruh yang signifikan antara kepercayaan terhadap minat muzzaki membayar zakat.

\section{Uji Simultan (Uji F)}

Uji-F digunakan untuk mengetahui pengaruh masing-masing variabel bebas terhadap variabel terikat. Hasil pengujian Uji-F tersebut adalah sebagai berikut:

Tabel 5. Hasil Uji F

\begin{tabular}{|c|c|c|c|c|c|c|c|}
\hline Model & & Sum of Squares & Df & & Mean Square & $\mathrm{F}$ & Sig. \\
\hline \multirow{3}{*}{1} & Regression & 70.650 & & 2 & 35.325 & 51.667 & $.000^{\mathrm{b}}$ \\
\hline & Residual & 64.952 & & 95 & .684 & & \\
\hline & Total & 135.602 & & 97 & & & \\
\hline
\end{tabular}

a. Dependent Variable: Minat

b. Predictors: (Constant), Kepercayaan, Pengetahuan

Sumber: Data Olahan SPSS (2019)

Dari tabel diatas menunjukkan bahwa F-hitung sebesar 51,667 sedangkan F-tabel pada taraf signifikan (a) $5 \%$ dengan df 1 sebesar $(\mathrm{k}-1=2-1)$, df 2 sebesar 95 (dk=n-k-1(98-2-1)), maka $F$ tabel diperoleh sebesar 3,94 maka $\mathrm{F}$ hitung > F tabel yaitu 51,667 > 3,94 yang berarti bahwa Ho ditolak. Artinya adalah bahwa variabel independen (pengetahuan dan kepercayaan) secara bersama-sama berpengaruh signifikan terhadap variabel dependen (minat muzzaki).

\section{Koefisien Korelasi}

Untuk mengetahui hubungan antara variabel bebas terhadap variabel terikat, maka digunakan koefisien korelasi dengan menggunakan bantuan komputer program SPSS for Windows versi 23.0 maka dapat dilihat pada tabel dibawah ini:

\section{Tabel 6. Analisis Korelasi}

\begin{tabular}{ccccc}
\hline Model & $\mathrm{R}$ & R Square & Adjusted R & Std. Error of the \\
Square & Estimate \\
\hline 1 & $.722^{\mathrm{a}}$ & .521 & .511 & .827 \\
\hline
\end{tabular}

Sumber: Data Olahan SPSS Versi 23.0 
Nilai $\mathrm{R}$ menunjukkan korelasi berganda antara variabel independen dengan variabel dependen. Dari tabel diatas diketahui nilai $\mathrm{R}$ sebesar 0,722 atau sebesar 72,2\%. Artinya adalah bahwa korelasi berganda antara variabel $\mathrm{X}$ (pengetahuan zakat dan kepercayaan) dengan variabel $\mathrm{Y}$ (minat muzakki) memiliki tingkat hubungan yang kuat.

Berdasarkan tabel di atas juga dapat diketahui nilai Adjusted $R$ Square sebesar 0,511 Artinya adalah ada pengaruh yang cukup besar antara variabel independen (pengetahuan dan kepercayaan) terhadap variabel dependen (minat muzakki) adalah sebesar 51,1\%. Sedangkan sisanya sebesar $48,9 \%$ dipengaruhi oleh variabel lain yang tidak dimasukkan dalam model ini.

Berdasarkan dari hasil penelitian di atas maka dapat dibuat pembahasannya sebagai berikut :

\section{Pengaruh Pengetahuan Zakat terhadap Minat Muzakki Membayar Zakat.}

Hasil penelitian ini menunjukkkan bahwa pengetahuan zakat berpengaruh positif dan signifikan terhadap minat muzakki membayar zakat di Baznas Kabupaten Kuantan Singingi dengan nilai t-hitung sebesar 5.951 dan nilai signifikansi sebesar 0,000 . Hasil penelitian ini sama dengan penelitian yang di lakukan oleh Nugroho \& Nurkhin (2019), dan Muhammad Nur \& Zulfahmi (2018).

\section{Pengaruh Kepercayaan kepada Baznas terhadap Minat Muzakki Membayar Zakat.}

Hasil penelitian ini menunjukkan bahwa kepercayaan kepada Baznas berpengaruh positif dan signifikan terhadap minat dengan nilai $\mathrm{t}$ hitung sebesar 3.943 dan nilai signifikansi sebesar 0.000. Hasil penelitian ini sama dengan penelitian yang dilakukan oleh Muhammad Nur \& Zulfahmi (2018), Rahkmania (2018), Satrio \& Siswantoro (2016), dan Yunus (2016).

\section{KESIMPULAN}

Berdasarkan hasil penelitian dan pembahasan di atas dapat di buat kesimpulan sebagai berikut:

1) Secara parsial, masing-masing variabel (pengetahuan zakat dan Kepercayaaan kepada Baznas) berpengaruh terhadap minat muzakki membayar zakat di Baznas Kabupaten kuantan Singingi.

2) Secara simultan, variabel pengetahuan zakat dan kepercayaan kepada Baznas berpengaruh terhadap minat muzakki membayar zakat di Baznas Kabupaten Kuantan Singingi.

3) Baznas Kabupaten Kuantan Singingi perlu meningkatkan transparansi dalam pengelolaan zakat yaitu dengan mempublikasikan sumber dana dan penyaluran zakatnya kepada masyarakat dengan cara memasang spanduk, baliho atau berupa iklan dimedia cetak maupun eloktronik.

4) Baznas Kabupaten Kuantan Singingi harus selalu melakukan sosialisasi kepada masyarakat agar tingkat pengetahuan zakat masyarakat tetap tinggi.

\section{DAFTAR PUSTAKA}

Al-Zuhaily, Wahbah. 1995. Zakat Kajian Berbagai Macam Mazhab. Remaja Rosdakarya. Bandung.

Bukhari. 2009. Motivasi Berzakat Masyarakat Kabupaten Bangga.

Djaali. 2012. Psikologi Pendidikan. Bumi Aksara. Jakarta. 
Leksono, Sonny. 2013. Penelitian Kualitatif Ilmu Ekonomi. Rajawali Pers. Jakarta.

Mandasari, Kartika. 2011. Analisis Faktor-Faktor Yang Mempengaruhi Minat Beli Konsumen Dalam Memilih Jasa Perhotelan (Studi kasus pada Hotel Grasia Semarang). Skripsi. Fakultas Ekonomi: Universitas Diponegoro Semarang.

Muhammad Nur, Mukhlis \& Zulfahmi. 2018. Pengaruh Pengetahuan, Pendapatan dan Kepercayaan terhadap Minat Muzakki dalam membayar Zakat di Baitul Maal Kota Lhokseumawe. Jurnal Ekonomi Regional Unimal, Vol. 03, No. 3, P. 89-99.

Nugroho, Aditya Surya \& Nurkhin, Ahmad. 2019. Pengaruh Religiusitas, Pendapatan, Pengetahuan Zakat terhadap Minat Membayar Zakat Profesi melalui Baznas dengan Faktor Usia sebagai Variabel Moderasi. Economic Education Analysis Journal, Vol. 8, No. 3, P. 955966.

Rakhmania, Nabila Akhiri. 2018. Pengaruh Pendapatan, Religiusitas, Kepercayaan, dan Pengetahuan terhadap Minat Muzakki mengeluarkan zakat melalui Lemabaga Amil Zakat di Kota Malang. Jurnal Ilmiah Mahasiswa FEB Universitas Brawijaya, Vol. 6, No. 2.

Sanusi, Anwar. 2014. Metodologi Penelitian Bisnis. Salemba Empat. Jakarta.

Satrio, Eka \& Siswantoro, Dodik. 2016. Analisis Faktor Pendapatan, Kepercayaan, dan Religiusitas dalam Mempengaruhi Minat
Muzakki untuk Membayar Zakat Penghasilan melalui Lembaga Amil Zakat. Simposium Nasional Akuntansi XIX, Lampung.

Slameto. 2012. Belajar dan FaktorFaktor Yang Mempengaruhinya. Rineka Cipta. Jakarta.

Taufiq Amir, Muhammad. 2005. Dinamika Pemasaran. Grafindo Persada. Jakarta.

Wibowo. 2006. Manajemen Perubahan. Grafindo Persada. Jakarta.

Yunus, Muhammad. 2016. Analisis Pengaruh Kepercayaan, Religiusitas, dan Kontribusi terhadap minat Pedagang mengeluarkan Zakat di Baitul Mall (Studi Kasus pada Pedagang Pasar di Pasar Los Lhokseumawe). At-Tawassuth, Vol. 1, No. 1, P. 96-124. 